\title{
Micromechanical finite element modelling of thermo-mechanical fatigue for P91 steels
}

\author{
Dong-Feng Li ${ }^{\mathrm{a}, \mathrm{b}}$, Richard A., Barrett ${ }^{\mathrm{b}}$, Padraic E. O’Donoghue ${ }^{\mathrm{c}}$, Chris J. Hyde ${ }^{\mathrm{d}}$, Noel P. \\ O’Dowd $^{\mathrm{e}}$, Sean B. Leen ${ }^{\mathrm{b}, *}$ \\ ${ }^{a}$ Graduate School, Harbin Institute of Technology, Shenzhen 518055, China \\ ${ }^{b}$ Mechanical Engineering, College of Engineering and Informatics, NUI Galway, Ireland \\ ${ }^{c}$ Civil Engineering, College of Engineering and Informatics, NUI Galway, Ireland \\ ${ }^{d}$ Department of Mechanical, Materials and Manufacturing Engineering, University of Nottingham, \\ Nottingham NG7 2RD, UK \\ ${ }^{e}$ Department of Mechanical, Aeronautical and Biomedical Engineering, Materials and Surface Science \\ Institute, University of Limerick, Ireland
}

\begin{abstract}
In this paper, the cyclic plasticity and fatigue crack initiation behaviour of a tempered martensitic ferritic steel under thermo-mechanical fatigue conditions is examined by means of micromechanical finite element modelling. The crystal plasticity based model explicitly reflects the microstructure of the material, measured by electronic backscatter diffraction. The predicted cyclic thermo-mechanical response agrees well with experiments under both in-phase and out-of-phase conditions. A thermo-mechanical fatigue indicator parameter, with stress triaxiality and temperature taken into account, is developed to predict fatigue crack initiation. In the fatigue crack initiation simulation, the out-of-phase thermo-mechanical response is identified to be more dangerous than in-phase response, which is consistent with experimental failure data. It is shown that the behaviour of thermo-mechanical fatigue can be effectively predicted at the microstructural level and this can lead to a more accurate assessment procedure for power plant components.
\end{abstract}

Keywords: Tempered martensite ferritic steels; Thermo-mechanical fatigue; Crystal plasticity; Fatigue crack initiation; Finite element; Power plant components

\section{Introduction}

In the past decade, the development of microstructural-sensitive modelling techniques has improved the understanding of mechanisms of material degradation in fatigue with the development of procedures to accurately assess structural integrity for cyclically-loaded materials and structural components [1-3]. The present study focuses on P91 steel (containing 9\% Cr, $1 \%$ Mo and the balance primarily Fe), which is a widely used power plant steel. Under the operating conditions of flexible power plants, the relevant components typically experience both cyclic mechanical and thermal loads (e.g. during start-up attemperation cycles [4, 5]) leading

*Corresponding author. Phone: +353 (0)87 2136086 Fax: +353 (0)91 563991

Email addresses: lidongfeng@hitsz.edu.cn (Dong-Feng Li), richard.barrett@nuigalway.ie (Richard A., Barrett), padraic.odonoghue@nuigalway.ie (Padraic E. O'Donoghue), Christopher.Hyde@nottingham.ac.uk (Chris J. Hyde), noel.odowd@ul.ie (Noel P. O'Dowd), sean.leen@nuigalway.ie (Sean B. Leen) 
potentially to thermo-mechanical fatigue (TMF) failure. However, in the design process for current materials and structures, TMF behaviour is not typically accounted for.

The cyclic plasticity and fatigue crack initiation (FCI) behaviour of P91 is examined here, focusing on accurate microstructure-based finite element (FE) modelling. For P91 and other similar power plant steels, isothermal fatigue (IF) studies at elevated temperature [6-16] have been extensively carried out. In these studies, considerable cyclic softening has been observed which results in the loss of material strength and this softening has been revealed to be associated with reduction of dislocation density and microstructural recovery at the subgrain level. Limited studies $[4,5,17]$ have focused on TMF response and phenomenological continuum models have been mainly used. In recent decades, microstructure-based finite element simulations [18-33] have been developed to study the fatigue response in metals, where the constitutive response at crystallographic level is typically represented by crystal plasticity theory. For the monotonic response of P91 and other high-chromium tempered martensite ferritic steels, crystal plasticity-based FE models [34-40] have been developed with focuses on simulating microscale inelastic deformation and failure. Recently, length-scale dependent crystal plasticity models $[39,33]$ have been developed and extended for P91 steel to account for the precipitate size effect on FCI under isothermal conditions. However, to our knowledge, microstructure-based modelling of TMF behaviour in P91 steels has not yet been performed. This is necessary in quantifying the fatigue mechanisms in current power plant components under intermittent thermo-mechanical loading conditions and optimising the key material parameters for next generation power plant. As the fatigue failure mechanisms in terms of formation and development of persistent slip bands [2] are associated with the microstructure, the present work presents such a micromechanical FE model to explicitly and accurately account for the crystallographic slip based inelastic deformation and failure for P91 steels.

The objectives of the present paper are as follows: (i) Develop a microstructure-based FE model to simulate cyclic plasticity behaviour for P91 steels and compare the cyclic thermomechanical response with experiments; (ii) Examine the microstructure-sensitive TMF failure behaviour, in terms of sites and number of cycles to fatigue crack initiation, based on a specific scale-consistent fatigue criterion.

\section{Experiment}

To characterise the TMF behaviour of P91 steel, a program of in-phase (TMF-IP) and outof-phase (TMF-OP) TMF tests have been carried out in the $400^{\circ} \mathrm{C}$ to $600^{\circ} \mathrm{C}$ temperature range [41]. The TMF setup is shown in Fig. 1a. The mechanical strain-temperature loading histories are illustrated schematically in Figs. $1 \mathrm{~b}$ and $\mathrm{c}$, with TMF tests conducted at strainranges of $1.0 \%, 0.8 \%$ and $0.6 \%$, at strain-rates of $3.3 \times 10^{-4} / \mathrm{s}$ and $2.5 \times 10^{-4} / \mathrm{s}$. The cyclic evolution of maximum tensile and compressive stress for sample (typical) TMF-IP and TMF-OP tests are presented in Fig. 2a, showing considerable cyclic softening for all test cases. Significant asymmetry of stress is observed with a higher maximum tensile stress for TMF-OP cases, due to the maximum strain coinciding with minimum temperature (Fig. 1c), giving a stronger response under the strain-controlled conditions. A comparison of the experimentally observed TMF maximum tensile stress with isothermal fatigue (IF) data at $400^{\circ} \mathrm{C}$ and $600^{\circ} \mathrm{C}$ is presented in Fig. 2b. The most significant effect of plastic-strain induced recovery (softening) is observed for IF behaviour at $600^{\circ} \mathrm{C}$. The experimental strain-life results in the $400^{\circ} \mathrm{C}$ to $600^{\circ} \mathrm{C}$ temperature range, for IF, TMF-IP and TMF-OP test conditions, are presented in Fig. 3. Although similar levels of recovery (softening) are observed for TMF-IP and TMF-OP 
cases, as presented in Fig. 2b, a lower fatigue life is observed for all TMF-OP cases, highlighting

(a)

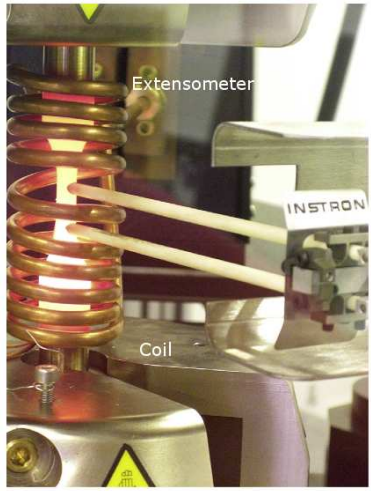

(b)

TMF in phase (TMF-IP):

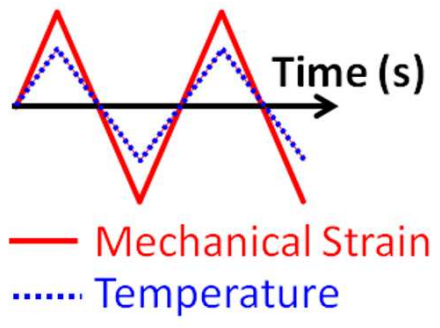

(c) TMF out of phase
(TMF-OP):

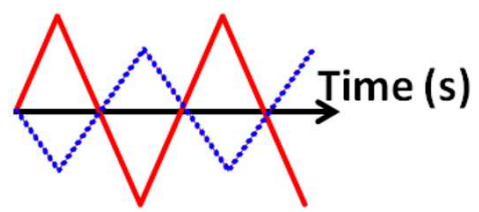

Figure 1: Illustration of TMF test for P91 steels with (a) TMF testing setup, (b) TMF in-phase (TMF-IP) and (c) TMF out-of-phase (TMF-OP).
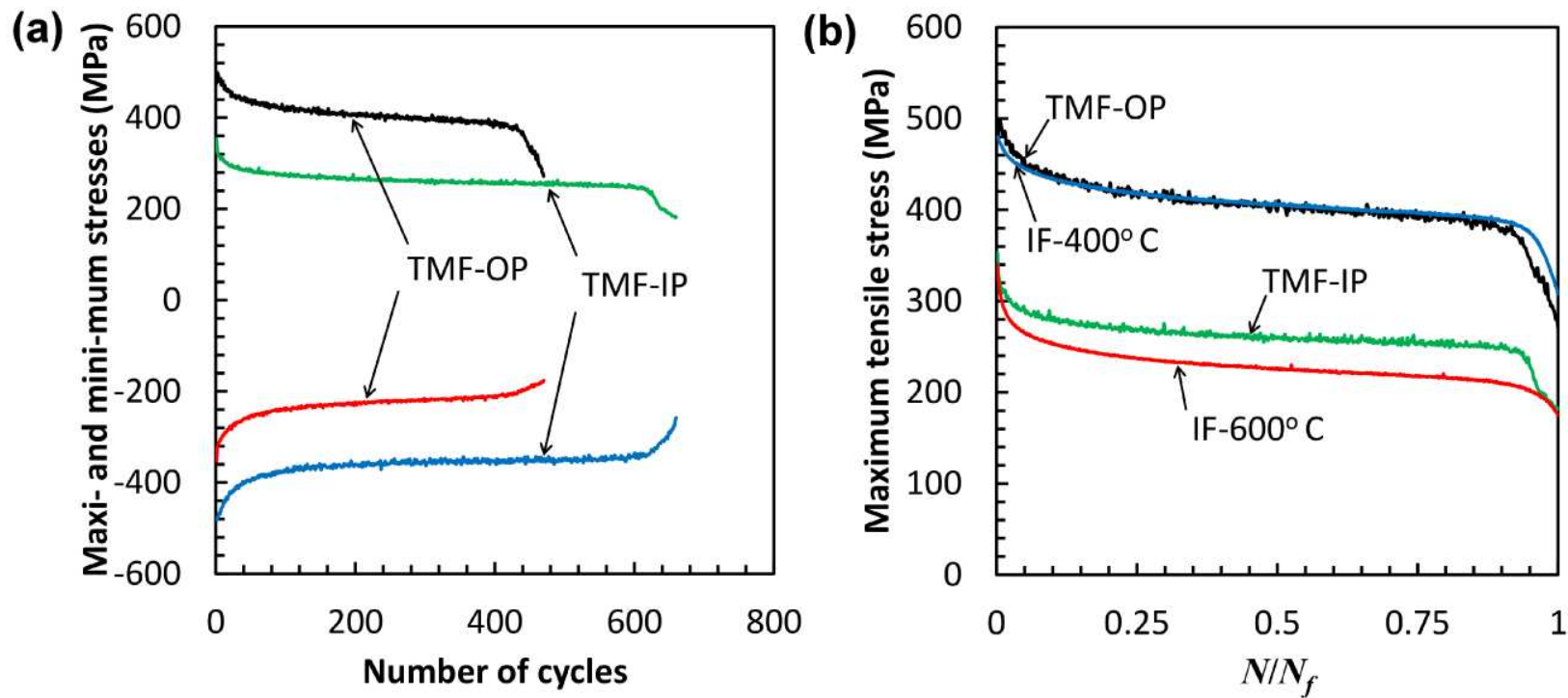

Figure 2: TMF data for P91 steels with (a) maximum and minimum stresses vs number of cycles and (b) comparison of maximum tensile stress data for both TMF and IF.

\section{Theory}

\subsection{Implementation of microstructure-sensitive finite element model for thermo-mechanical} fatigue

In the present work, a microstructure-based FE modelling methodology is developed to study TMF behaviour in P91 steels. Fig. 4a shows the material microstructure acquired by electron backscatter diffraction (EBSD) measurement with a planar dimension of $176 \times$ $111 \mu \mathrm{m}^{2}$. In Fig. 4a, crystallographic orientations of different grains are distinguished by an inverse pole map. The corresponding FE model is shown in Fig. 4b with the measured 


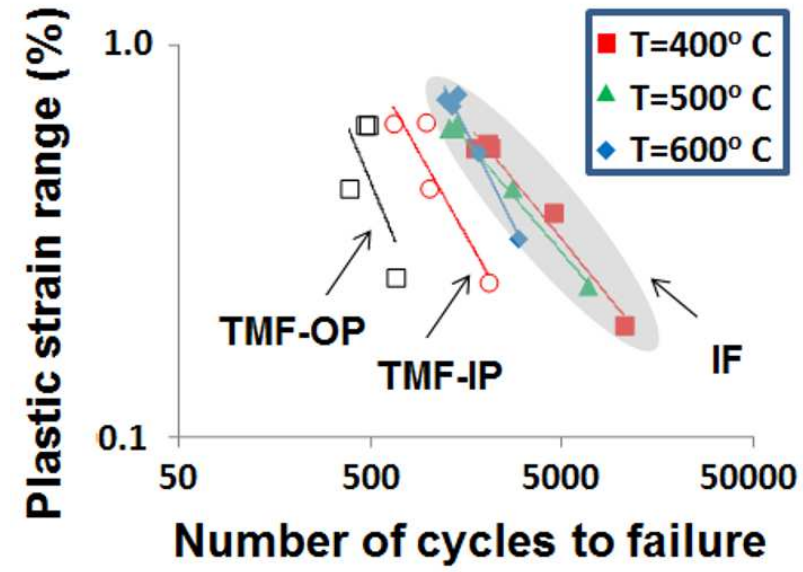

Figure 3: Fatigue life data for P91 steels under both TMF and IF conditons.

(a) EBSD measurement (b)

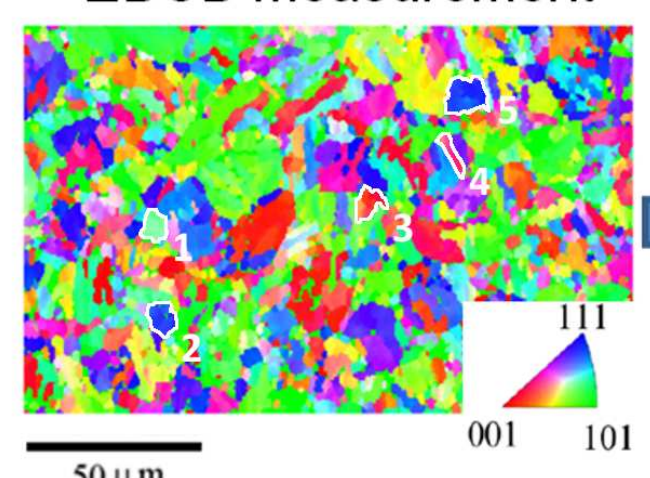

Euler angle

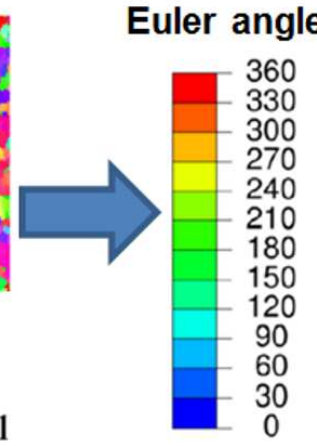

Finite element model

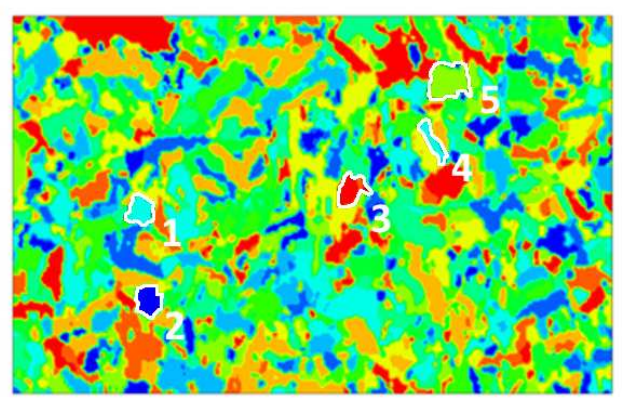

Figure 4: Micromechanical finite element model for thermo-mechanical fatigue (TMF) in P91 steels with (a) microstructure morphology measured by EBSD (here the plot is for the perpendicular direction to the sample surface) and (b) the spatial distribution of the second Euler angle in a polycrystal finite element model.

grain-level details in a representative volume element (RVE). The Euler angles [42] are used to represent crystallographic orientations in the polycrystal FE model (Fig. 4b). As described in detail by Li et al. [39], the measured Euler angles of the microstructure are input directly into the FE model, element by element, so that the crystallographic information in the FE model exactly matches the measured one. To illustrate this, five grains (blocks) are highlighted in both the EBSD (Fig. 4a) and the FE representation (Fig. 4b), clearly showing direct one-to-one correlation of grains. Note that the dimension of the RVE is appropriate such that a representative macroscopic response can be obtained using the polycrystal FE model as shown in the earlier study [39]. The representativeness of an EBSD-based RVE relies on the satisfaction of the condition that the RVEs for different sample positions (with same dimension) lead to consistent aggregative stress-strain response. It is indicated in the previous work [39] that, with increasing RVE size from the current RVE, almost unchanged aggregative stress-strain response is achieved. Following the approach in Ref. [42], the FE model uses regular 3D brick elements ( 8 nodes and cubic shape with edge length of $0.5 \mu \mathrm{m}$ ) with periodic boundary conditions in both in-plane and out-of-plane directions. Note that the RVE is 3$\mathrm{D}$ with the third dimension generated by extending the 2-D FE mesh in the out-of-plane 
direction by one element thick. Therefore, the current RVE has a columnar grain shape. It has been discussed by Li et al. [39] that such an RVE is appropriate for in-plane loading case to account for the most relevant in-plane grain interactions. The crystal plasticity model discussed in Section 3.2 is then used to represent the constitutive response of each single grain and considers two cases, TMF in-phase (TMF-IP) and TMF out-of-phase (TMF-OP) as shown in Figs. 1b and c.

\subsection{Crystal plasticity-based constitutive formulation}

The crystal plasticity model presented in Refs. [39, 33] for P91 steels has been used to describe the constitutive response for P91 steels and the temperature dependent isotropic and kinematic hardening is included here to describe the TMF response. In the current work, the elastic response of the material is linear as in Ref. [39] and the evolution of inelastic slip is represented by a thermally activated flow rule [43] as follows

$$
\dot{\gamma}^{\alpha}=\dot{\gamma}_{0} \exp \left\{-\frac{F}{k T}\left\langle 1-\left\langle\frac{\left|\tau^{\alpha}-B^{\alpha}\right|-S^{\alpha}}{\tau_{0}}\right\rangle^{p}\right\rangle^{q}\right\} \operatorname{sgn}\left(\tau^{\alpha}-B^{\alpha}\right),
$$

where $\dot{\gamma}^{\alpha}$ is slip rate; $\tau^{\alpha}$ and $S^{\alpha}$ are resolved shear stress and slip resistance, respectively; $F$, $k$ and $T$ are the thermal activation energy for a material, Boltzmann constant and absolute temperature, respectively; $p, q$ and $\dot{\gamma}_{0}$ are the exponents and pre-exponential constants; $\tau_{0}$ is the critical shear stress; the brackets $\langle$.$\rangle indicate that \langle x\rangle \equiv x$ for $x>0$ and $\langle x\rangle \equiv 0$ for $x \leq 0$; $B^{\alpha}$ and $S^{\alpha}$ are back stress and slip resistance for the slip system, $\alpha$, respectively.

An Armstrong-Fredrick type kinematic hardening rule [43-46] is adopted to describe the evolution of the back stress, $B^{\alpha}$, as follows

$$
\dot{B}^{\alpha}=h_{b} \dot{\gamma}^{\alpha}-\frac{r_{D}}{S^{\alpha}} B^{\alpha}\left|\dot{\gamma}^{\alpha}\right|,
$$

where $h_{b}$ and $r_{D}$ are material constants. Here, $h_{b}$ is set to be temperature dependent in order to capture the TMF response. Based on a generalised Taylor relation [47], slip resistance is given by

$$
S^{\alpha}=\mu b \sqrt{\sum_{\beta=1}^{M} h_{0}\left[\omega_{1}+\left(1-\omega_{2}\right) \delta^{\alpha \beta}\right]\left(\rho_{S e}^{\beta}+\rho_{S s}^{\beta}+\rho_{G}^{\beta}\right)},
$$

where $\mu$ and $b$ are the shear modulus and the magnitude of the Burgers vector, respectively; $\rho_{S e}^{\beta}, \rho_{S s}^{\beta}$ and $\rho_{G}^{\beta}$ are the edge part of statistically stored dislocation (SSD) density, the screw part of SSD density and the screw part of geometrically necessary dislocation (GND) density for the slip system $\beta$, respectively; $h_{0}$ is a coefficient indicating the strength of dislocation pair interactions; $\omega_{1}$ and $\omega_{2}$ are interaction constants and $\delta^{\alpha \beta}$ is the Kronecker delta. Note here that only the shear modulus, $\mu$, is a function of temperature such that the isotropic hardening is temperature dependent at the grain level. In the present work, $\omega_{1}=\omega_{2}=1$ which implies dislocations interact equally.

Based on previous studies [39, 48], the critical shear stress, $\tau_{0}$, is given as follows

$$
\tau_{0}=\hat{\tau}_{0}+c_{\tau} \sqrt{\sum_{\beta=1}^{M}\left(\rho_{S e}^{\beta}+\rho_{S s}^{\beta}+\rho_{G}^{\beta}\right)},
$$


where $\hat{\tau}_{0}$ is the critical shear stress in the absence of dislocation barriers and $c_{\tau}$ is a material constant. As in previous studies $[33,49,50]$, the evolution of $\rho_{S e}^{\alpha}$ and $\rho_{S s}^{\alpha}$ are given as follows

$$
\begin{aligned}
& \dot{\rho}_{S e}^{\alpha}=\left[\frac{K_{e}}{b} \sqrt{\sum_{\beta=1}^{M}\left(\rho_{S e}^{\beta}+\rho_{S s}^{\beta}+\rho_{G}^{\beta}\right)}-d_{e} \rho_{S e}^{\alpha}\right]\left|\dot{\gamma}^{\alpha}\right|, \\
& \dot{\rho}_{S s}^{\alpha}=\left[\frac{K_{s}}{b}\left(1-\frac{\pi d_{s}^{2}}{4} \rho_{S s}^{\alpha}\right) \sqrt{\sum_{\beta=1}^{M}\left(\rho_{S e}^{\beta}+\rho_{S s}^{\beta}+\rho_{G}^{\beta}\right)}-d_{s} \rho_{S s}^{\alpha}\right]\left|\dot{\gamma}^{\alpha}\right|,
\end{aligned}
$$

where $K_{e}$ and $K_{s}$ are two coefficients of dislocation generation for the slip system $\alpha$, and $d_{e}$ and $d_{s}$ are two coefficients relating to the annihilation of edge and screw dislocations, respectively. In this work, $K_{s}=2 K_{e}$ as used in the previous work [49], based on slip line measurements [51, 52]. Hereafter, only $K_{e}$ will be presented. Note that the dislocation densities are temperature dependent in the current paper. Such effect is implicitly captured via the effect of temperature on slip rate in Eq. (1). The evolutions of dislocation densities in Eqs. (5a) and (5b) depend on slip rate and are thus temperature-dependent. Note that, as dicussed by Mughrabi [53], for example, for low cycle fatigue, as in this work, the fraction of reversible slip relative to total slip is small.

The evolution of GND density, $\rho_{G}^{\alpha}$, depends on plastic strain gradient and the details can be found in previous work $[39,33]$. The user element subroutine (UEL), implemented within a commercial FE code [54], is then used to take the evolution of GND densities and the length scale dependency into account in the constitutive relations above. In order to incorporate the thermo-mechanical effect into the CPFE micro-mechanical model, the specific temperature evolution corresponding to in-phase or out-of-phase conditions is allowed in the UEL.

During TMF, the increment of accumulated equivalent plastic strain $[33,39,46]$ is defined as

$$
d \bar{\varepsilon}_{p}=\left(\frac{2}{3} \mathbf{D}^{p}: \mathbf{D}^{p}\right)^{\frac{1}{2}} d t
$$

where $d t$ is the time increment and $\mathbf{D}^{p}$ is plastic strain rate defined as

$$
\mathbf{D}^{p}=\frac{1}{2} \sum_{\alpha=1}^{N} \dot{\gamma}^{\alpha}\left[\mathbf{F}^{e} \mathbf{m}^{\alpha} \otimes \mathbf{n}^{\alpha}\left(\mathbf{F}^{e}\right)^{-1}+\left(\mathbf{F}^{e}\right)^{-T} \mathbf{n}^{\alpha} \otimes \mathbf{m}^{\alpha}\left(\mathbf{F}^{e}\right)^{T}\right] .
$$

Here, $\mathbf{F}^{e}$ is the elastic deformation gradient, $\mathbf{m}^{\alpha}$ and $\mathbf{n}^{\alpha}$ are slip direction and slip plane normal of the slip system, $\alpha$, respectively, $\otimes$ is dyadic product, and superscripts ' -1 ', ' $T$ ' and ' $-T$ ' indicate the tensor operations of inverse, transpose and inverse transpose, respectively.

\subsection{Thermo-mechanial fatigue indicator parameter}

The present work focuses on fatigue behaviour of P91 steels. Typically, the total fatigue life, $N_{f}$, can be decomposed as follows

$$
N_{f}=N_{i}+N_{p}
$$

where $N_{i}$ is the number of cycles required to initiate a fatigue crack and $N_{p}$ is the number of cycles to propagate the fatigue crack up to failure [1]. Under low cycle fatigue conditions at elevated temperature for P91 steels, it has been shown in Refs. [55-57] that $N_{i}$ can make 
up 10-20\% total fatigue life and that typically micro-cracking initiation is characterised by multiple crack initiation sites. In the current work, attention is focused on the fatigue crack initiation (FCI) in P91 steels. FCI is assumed to occur when a critical value of local accumulated crystallographic slip is achieved. Note that the cumulative effective crystallographic slip-based fatigue indicator parameter (using rate of plastic deformation tensor) used here has been presented and validated against IF test data at $600^{\circ} \mathrm{C}$ in Ref. [33]. In the latter, an initiation life was inferred from experimental data via the fitting of a Kocks-Mecking dislocation density evolution equation to the measured softening and was found to give initiation lives of about $10 \%-20 \%$ of total life, consistent with those observed by other authors for the same material and temperature. The method presented in Ref. [33] is essentially an extension of a similar approach by Manonukul and Dunne [18], who first proposed a cumulative effective crystallographic slip parameter for low- and high-cycle fatigue, including mean stress effects, and for high temperature. A similar approach [32] has also been successfully validated against test data for FCI in $\mathrm{CoCr}$ alloy and the strain gradient CPFE plasticity method was shown to successfully capture measured grain size effect on FCI and hysteresis loop (i.e. cyclic behaviour), as well for micro-scale high-cycle fatigue test specimens [58]. Next we derive the formulation of the fatigue indicator parameter at the microstructural level.

The mechanism on which the FCI model is predicated is localised, cyclic accumulation of plastic deformation via crystallographic slip, causing gradual material degradation via microvoid nucleation, growth, coalescence and hence micro-crack propagation [59, 60] for low cycle fatigue. In the present work, FCI is assumed to occur when a critical value of local accumulated crystallographic slip is reached. The accumulated inelastic deformation is designated as a fatigue indicator parameter (FIP). It is expected that FCI will have additional dependencies on the local stress state (triaxiality) and temperature variation as micro-void nucleation, growth and coalescence will be affected strongly by them. For P91 steels, a recent experimental study [62] has shown the temperature dependence of uniaxial failure strain $\varepsilon_{f}$, which can be expressed as a function of temperature between $400^{\circ} \mathrm{C}$ and $600^{\circ} \mathrm{C}$ as follows,

$$
\varepsilon_{f}=\varepsilon_{f}^{600}[1+\kappa(T-873)],
$$

where $\varepsilon_{f}^{600}$ is the uniaxial failure strain at $600^{\circ} \mathrm{C}$ and $\kappa=1.25 \times 10^{-3} / \mathrm{K}$ based on the experimental data [62] for a strain rate of $3.3 \times 10^{-4} / \mathrm{s}$. Under TMF conditions, both temperature and local stress triaxiality vary. It is then possible to propose a fatigue indicator parameter for TMF, as a function of number of cycles $N$, given by

$$
\widetilde{\varepsilon}_{p}(N)=\sum_{n=1}^{N} \int_{t_{n}}^{t_{n+1}}\left(\frac{2}{3} \mathbf{D}^{p}: \mathbf{D}^{p}\right)^{\frac{1}{2}} \exp \left(\frac{3}{2} \frac{\sigma_{m}}{\sigma_{e q}}-\frac{1}{2}\right)[1+\kappa(T-873)]^{-1} d t,
$$

where $\sigma_{m}$ is the hydrostatic stress, $\sigma_{e q}$ is the von Mises stress, $t_{n}$ and $t_{n+1}$ represent the start time of the $n^{\text {th }}$ and $(n+1)^{\text {th }}$ cycle, respectively.

With the newly defined variable, $\widetilde{\varepsilon}_{p}$, the fatigue criterion is written as

$$
\widetilde{\varepsilon}_{p}^{\max }\left(N_{i}\right)=\widetilde{\varepsilon}_{c r i t},
$$

where $\widetilde{\varepsilon}_{c r i t}$ is a material constant representing micro-scale fatigue crack initiation, $\widetilde{\varepsilon}_{p}^{\max }$ is the maximum value of $\widetilde{\varepsilon}_{p}$ over all spatial locations. The material constant, $\widetilde{\varepsilon}_{c r i t}$, can be identified under IF condition (at $600^{\circ} \mathrm{C}$ ). The $N_{i}$ for other experiments (including real applications) can then be predicted by inversely using Eq. (11). 


\subsection{Model calibration and material parameters}

Uniaxial isothermal LCF experimental data [16] for a strain rate of $3.3 \times 10^{-4} / \mathrm{s}$ are used to calibrate the material parameters in the crystal plasticity based FE model. Table 1 gives the temperature dependent constants including single crystal anisotropic elastic constants and a kinematic hardening parameter. Table 2 gives the temperature independent parameters which are identical to those used in a recent study [33]. As in previous studies [39, 33], the initial dislocation density, $\rho_{0}$, is set to $4.2 \times 10^{8} \mathrm{~mm}^{-2}$. Here, the initial dislocation density as in the work of Li et al. [39] is consisting of initial GND density (set to zero) and initial SSD density (non-zero) with edge and screw parts equally assigned. In the calibration, three temperatures are examined and Figs. 5a-c show the comparison between the simulated first-cycle stressstrain hysteresis loops and the experimental data at $400^{\circ} \mathrm{C}, 500^{\circ} \mathrm{C}$, and $600^{\circ} \mathrm{C}$, respectively, for a mechanical strain range of $1 \%$. Figs. 5 d-f show similar comparison in the sixth cycle. Note that for other mechanical strain ranges the modelling prediction agrees equally well with the isothermal LCF data, although not shown here. The crystal plasticity based FE model has been further validated through the use of in-situ neutron diffraction measurement and EBSD measurement $[63,64,40]$ at room temperature under monotonic loading. Note that the temperature dependent material parameters as given in Table 1 have been calibrated at three temperatures. The TMF effect, then, can be acquired in the CPFE micro-mechanical model by describing the temperature dependencies of these parameters as quadratic interpolations in the UEL.

The model is essentially based on the isothermal calibration at $600^{\circ} \mathrm{C}$ from the work of Li et al. [33], with introduction of temperature dependence for the elastic constants and $h_{b}$ of Table 2, for the $400^{\circ} \mathrm{C}$ and $500^{\circ} \mathrm{C}$ IF cases. In the work of Li et al. [33], fitting of the model is based on comparison with the stress-strain cycles over the first 6 cycles. As discussed in Refs. $[6,7,11]$, a reduction of dislocation density has been observed during cyclic deformation of P91 at elevated temperature. For the half-life cycles, in order to capture the significant long-term cyclic softening, two parameters, initial dislocation density $\left(\rho_{0}\right)$ and critical shear stress $\left(\hat{\tau}_{0}\right)$, are evolved to reduced values. Essentially, the re-calibration method is simply to only evolve (reduce) the initial dislocation density to one-fifth of the value for cycles 1 to 6 and the critical shear stress to a value of $420 \mathrm{MPa}$, to simulate the long-term cyclic softening. The reduction ratio of initial dislocation density used is consistent with the experimental data in the literature $[7,66]$. The reduction of the critical shear stress is physically motivated by precipitate coarsening, which leads to increased obstacle (precipitate) spacing and hence (based on Orowan strengthening mechanism [67]) decreased shear strength. No operations are applied on the internal variables, e.g., the back stress still evolves from zero initial value for the half-life cycle simulation, which starts from zero stress-strain point. This approach has been shown to give consistently excellent correlation at the half-life (number of cycles varies with tests conditions, viz. temperature, strain-range) for both the $600^{\circ} \mathrm{C}$ IF tests, across a range of strain-ranges, in Ref. [33], and as shown in the following section for (i) the $400^{\circ} \mathrm{C}$ and $500^{\circ} \mathrm{C}$ IF tests and (ii) the TMF-OP and TMF-IP tests.

Table 1: Temperature dependent parameters.

\begin{tabular}{cccccccc}
\hline $\begin{array}{c}\text { Temperature } \\
{ }^{\circ} \mathrm{C}\end{array}$ & $C_{11}$ & $C_{12}$ & $C_{44}$ & $\mathrm{E}$ & $\mu$ & $\nu$ & $h_{b}$ \\
\hline 400 & 178.8 & 112.4 & 104.0 & 92.0 & 104.0 & 0.386 & 6600 \\
500 & 157.0 & 102.5 & 101.0 & 76.0 & 101.0 & 0.395 & 6500 \\
600 & 140.5 & 95.0 & 90.2 & 63.8 & 90.2 & 0.4035 & 5800 \\
\hline
\end{tabular}


Table 2: Temperature independent constants.

\begin{tabular}{cccccccccccc}
\hline$\dot{\gamma}_{0}$ & $p$ & $q$ & $F$ & $\hat{\tau}_{0}$ & $c_{\tau}$ & $b$ & $h_{0}$ & $K_{e}$ & $d_{e}$ & $d_{s}$ & $r_{D}$ \\
$\mathrm{~s}^{-1}$ & - & - & $\mathrm{kJ} / \mathrm{mol}$ & $\mathrm{MPa}$ & $\mathrm{N} / \mathrm{mm}$ & $\mathrm{nm}$ & - & - & - & - & $\mathrm{MPa}$ \\
\hline $10^{6}$ & 0.5 & 1.25 & 270 & 490 & $2.7 \times 10^{-3}$ & 0.248 & 0.014 & 2500 & 50 & 250 & 200 \\
\hline
\end{tabular}
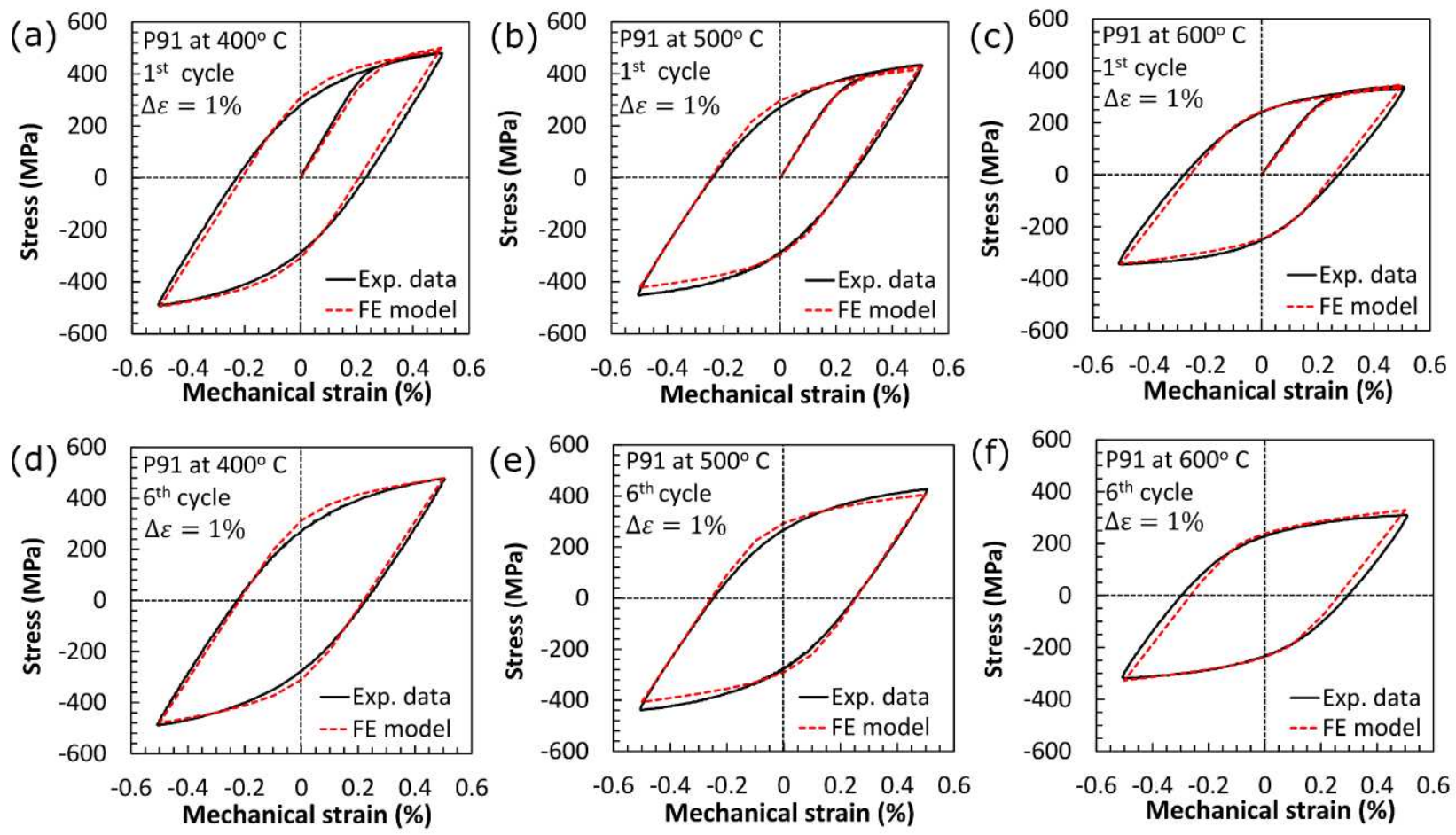

Figure 5: Hystersis loop of the calibrated polycrystal $\mathrm{FE}$ model and isothermal cyclic experiment with the first loop at (a) $400^{\circ} \mathrm{C}$, (b) $500^{\circ} \mathrm{C}$ and (c) $600^{\circ} \mathrm{C}$, and the sixth loop at (d) $400^{\circ} \mathrm{C}$, (e) $500^{\circ} \mathrm{C}$ and (f) $600^{\circ} \mathrm{C}$ for the mechanical strain range of $1 \%$.

\section{Results and discussion}

\subsection{Predicted cyclic response under thermo-mechanical fatigue condition}

The material parameters that were calibrated using the isothermal fatigue data are now used to predict the TMF response. Fig. 6 shows the comparison between the predicted hysteresis stress-strain loops and experimental data [16] under TMF-IP loading. More details of the TMF testing method can be found elsewhere [65]. Since the temperature dependent material constants are calibrated at three temperatures, the TMF simulation uses quadratically interpolated values at other temperatures. In Figs. $6 \mathrm{a}$ and b, the predicted and measured hysteresis loops in the first and sixth cycles, respectively, for the mechanical strain range of $1.0 \%$, are compared and very good agreement is achieved.

Due to the lengthy computation time, the present FE model is initially applied to simulate only up to six cycles using the material parameters given in Table 1 and Table 2. In order to examine the TMF behaviour at a relatively large number of cycles, the present work samples the experimental TMF response at the half-life (e.g. $250^{\text {th }}$ cycle for $1 \%$ strain-range). Fig. 6c shows the comparison between the model and experiment with a good agreement achieved. Figs. 6d-f and g-i show the simulated stress-strain loops and the associated experimental cycles for mechanical strain ranges of $0.8 \%$ and $0.6 \%$, respectively. Note that the same values of the re-calibrated material parameters as given above for a mechanical strain range of $1 \%$ are used 

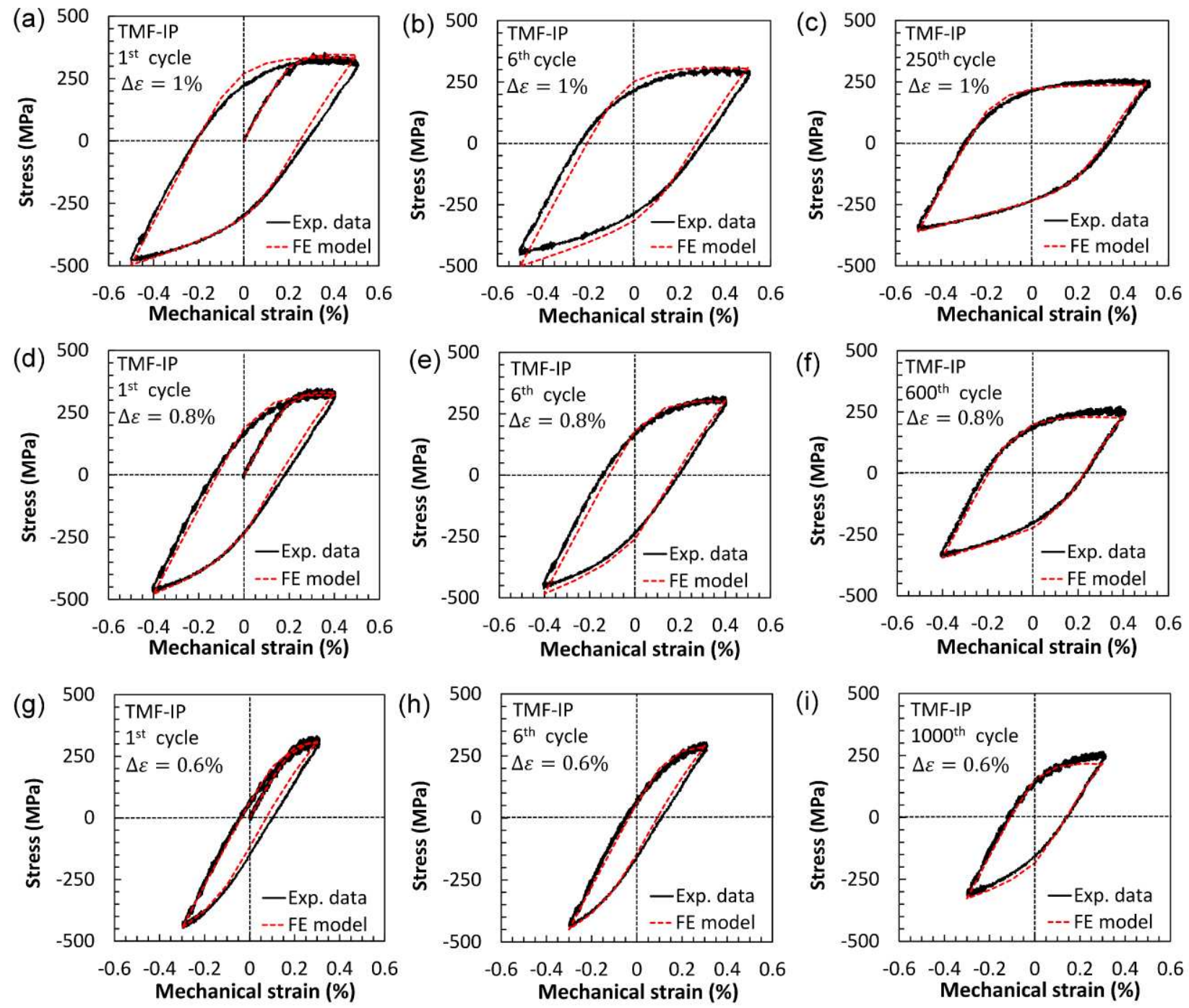

Figure 6: Simulated and measured stress-strain loops for a P91 steel under TMF-IP loading with (a), (b) and (c) showing the first, sixth and $250^{\text {th }}$ hysteresis loops, respectively, for mechanical strain range $\triangle \varepsilon=1.0 \%$; and (d), (e) and (f) showing the first, sixth and $600^{\text {th }}$ hysteresis loops, respectively, for $\triangle \varepsilon=0.8 \%$; and (g), (h) and (i) showing the first, sixth and $1000^{\text {th }}$ hysteresis loops, respectively, for $\triangle \varepsilon=0.6 \%$.

in the model to represent the TMF response for the cyclic 'half' lives with mechanical strain ranges of $0.8 \%$ and $0.6 \%$ (600 and 1000 cycles, respectively). In this work, for TMF, and in the previous work, for IF [33], attention is limited to cycles up to the half-life. The half-life simulation is performed for only one cycle as its objective is to obtain the FIP increment at half-life cycle, which is used to estimate the overall FIP evolution.

Fig. 7 shows the comparison between the prediction of stress-strain loops and measurement [16] under TMF-OP loading in the first, sixth and half life cycles for the same three mechanical strain ranges. Note that the same values of recalibrated material parameters as given above are used in the TMF-OP simulations to represent the half life cyclic response. Good agreement between model and experiment can be seen in the figure though agreement is not quite as close as for the IP data at the half life.

Note that the primary mechanisms of softening include coarsening of microstructure (laths, precipitates), annihilation of low-angle boundary dislocations, associated decrease in dislocation density and fatigue micro-cracking and micro-void damage. Annihilation of dislocations 

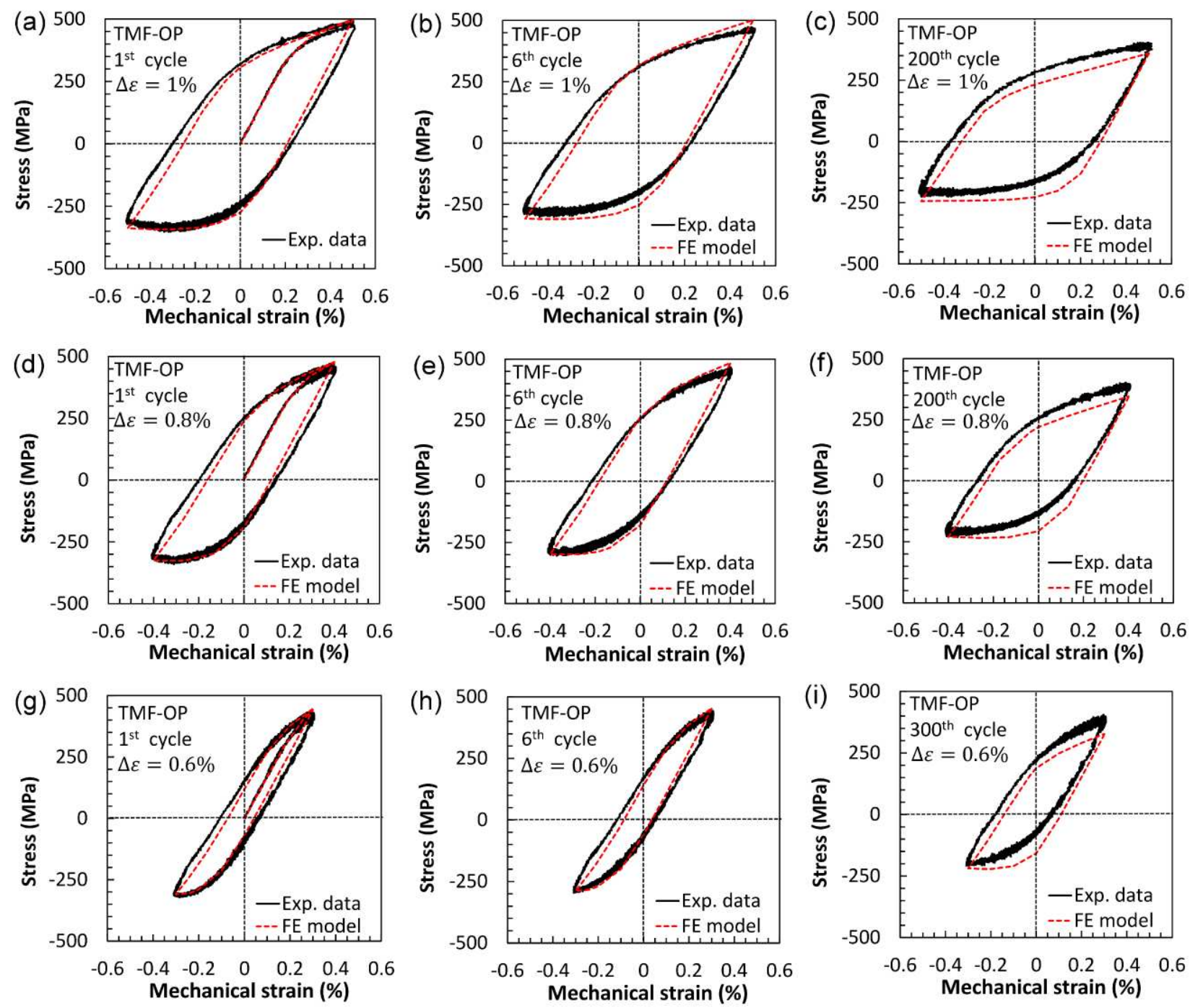

Figure 7: Simulated and measured stress-strain loops for a P91 steel under TMF-OP loading with (a), (b) and (c) showing the first, sixth and $200^{\text {th }}$ hysteresis loops, respectively, for $\triangle \varepsilon=1.0 \%$; and (d), (e) and (f) showing the first, sixth and $200^{\text {th }}$ hysteresis loops, respectively, for $\triangle \varepsilon=0.8 \%$; and $(\mathrm{g}),(\mathrm{h})$ and (i) showing the first, sixth and $300^{\text {th }}$ hysteresis loops, respectively, for $\triangle \varepsilon=0.6 \%$.

(Eqs. 5a and 5b) is modelled here, as demonstrated in the results of Figs. 5-7, which show physically-based softening over the first 6 cycles, albeit small, due to the long-term nature of this softening mechanism. The effect of long-term cyclic softening has been studied in this paper through the evolution of the two crystal plasticity material parameters, critical shear stress and initial dislocation density. Rather than explicitly simulating this physical process, at significant computational expense, the model is calibrated for the initial 6 cycles and then these two parameters are evolved to the half-life; this allows assessment of the effect of cyclic softening localisation phenomena for the microstructure-based FIP evolution. We have not measured this evolution of these two parameters, but this certainly permits simulation of the effect of cyclic softening consistently. Nonetheless, ongoing current and future work is targeted at the development of methods for explicit modelling of microstructure evolution, using phase field methods for example. Also, some current work by the authors [68] is focused on the development of more complex dislocation density evolution models for a more accurate physical representation of the complex strengthening and softening mechanisms of P91 high 
temperature cyclic behaviour. Future work will investigate implementation of these in CPFE for P91. The focus of the present work is to explore the salient differences in cyclic behaviour between TMF-OP, TMF-IP and IF, as well as to investigate the ability of an IF-calibrated model to predict TMF behaviour.

\subsection{Local response simulation}
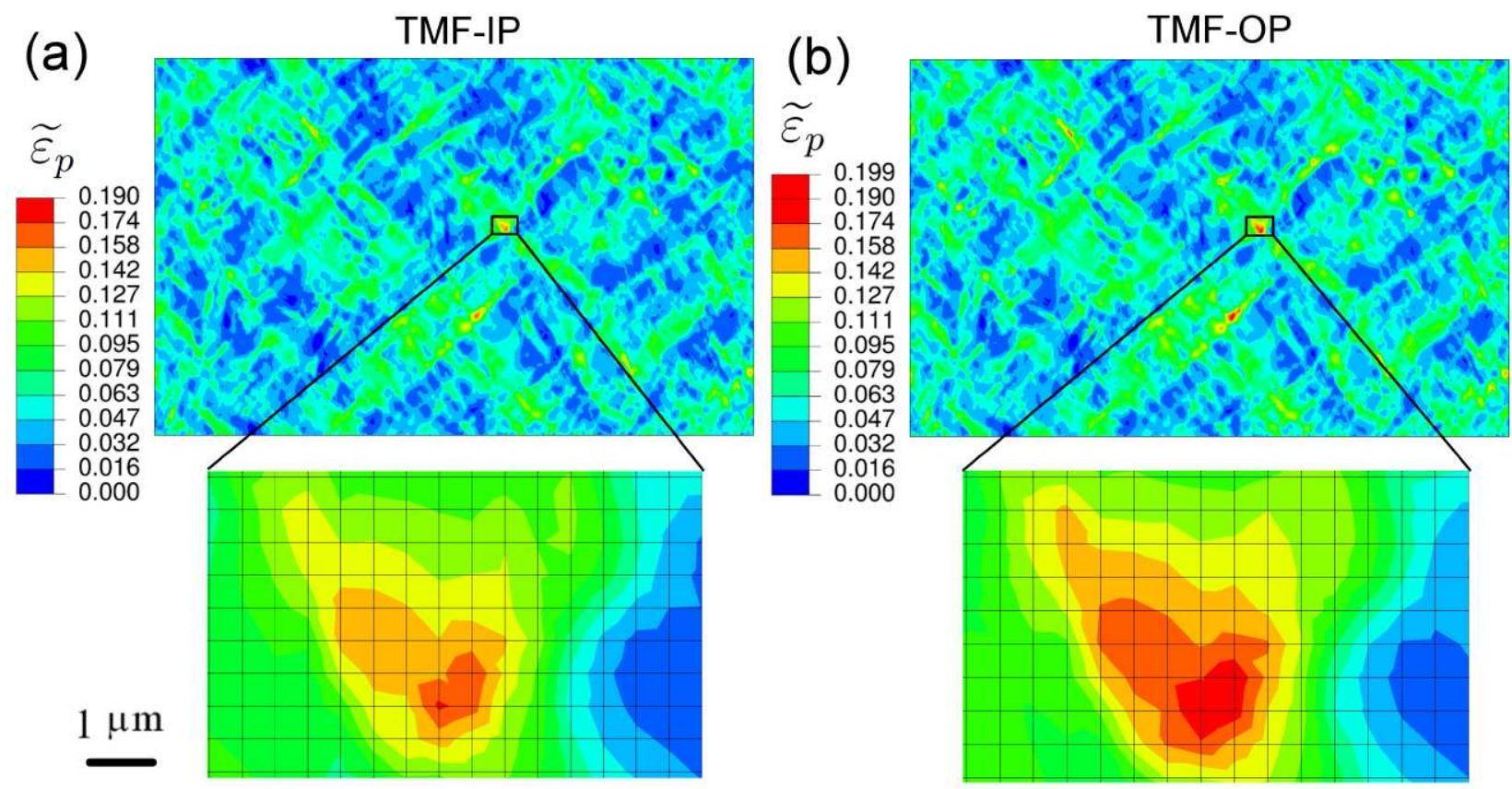

Figure 8: Simulated local response for $\triangle \varepsilon=1 \%$ with (a) and (b) showing the distribution of modified plastic strain $\widetilde{\varepsilon}_{p}$ at maximum stress instant in the $6^{\text {th }}$ cycle for TMF-IP and TMF-OP, respectively.

Fig. 8 shows the localisation of accumulated FIP from the FE model for a strain range of 1\%. In Figs. 8a and b, the contour distributions of $\widetilde{\varepsilon}_{p}$ for TMF-IP and TMF-OP are presented, respectively. The inhomogeneous distribution is attributed to grain interaction during cyclic deformation. In order to clearly see the difference between TMF-IP and TMF-OP, Fig. 8 also shows the zoomed-in contour plots at the same location with the finite element grid included. The maximum value identified here is the FIP for this analysis. It can be seen that the TMFOP case has a larger local response of $\widetilde{\varepsilon}_{p}$ than TMF-IP. Note that multiple sites with 'equally' high values of $\widetilde{\varepsilon}_{p}$ have been predicted in Fig. 8, consistent with experimental observations of P91 crack initiation [57].

\subsection{The evolution of fatigue indicator parameter and the prediction of fatigue crack initiation}

Figs. 9a and $\mathrm{b}$ show the evolution of FIP for the first six cycles with a linear relationship observed under both TMF-IP and TMF-OP for all three strain ranges considered. Thus the increment in FIP per cycle in each case at the early stage of loading is relatively constant and these averaged values are presented in Table 3. In addition, the FIP increment was also calculated in the later (half-life) cycle analyses (discussed in Section 4.1) and these results are also provided in Table 3.

In fact, although the trend looks linear for the first 6 cycles (Fig. 9) with almost constant increment in FIP per cycle, the simulation of half-life cycles shows that the FIP increment per cycle changes at the number of cycles corresponding to the half-life (Table 3), due to the long-term softening. Hence, it is necessary to integrate the FIP using the sampled values of 

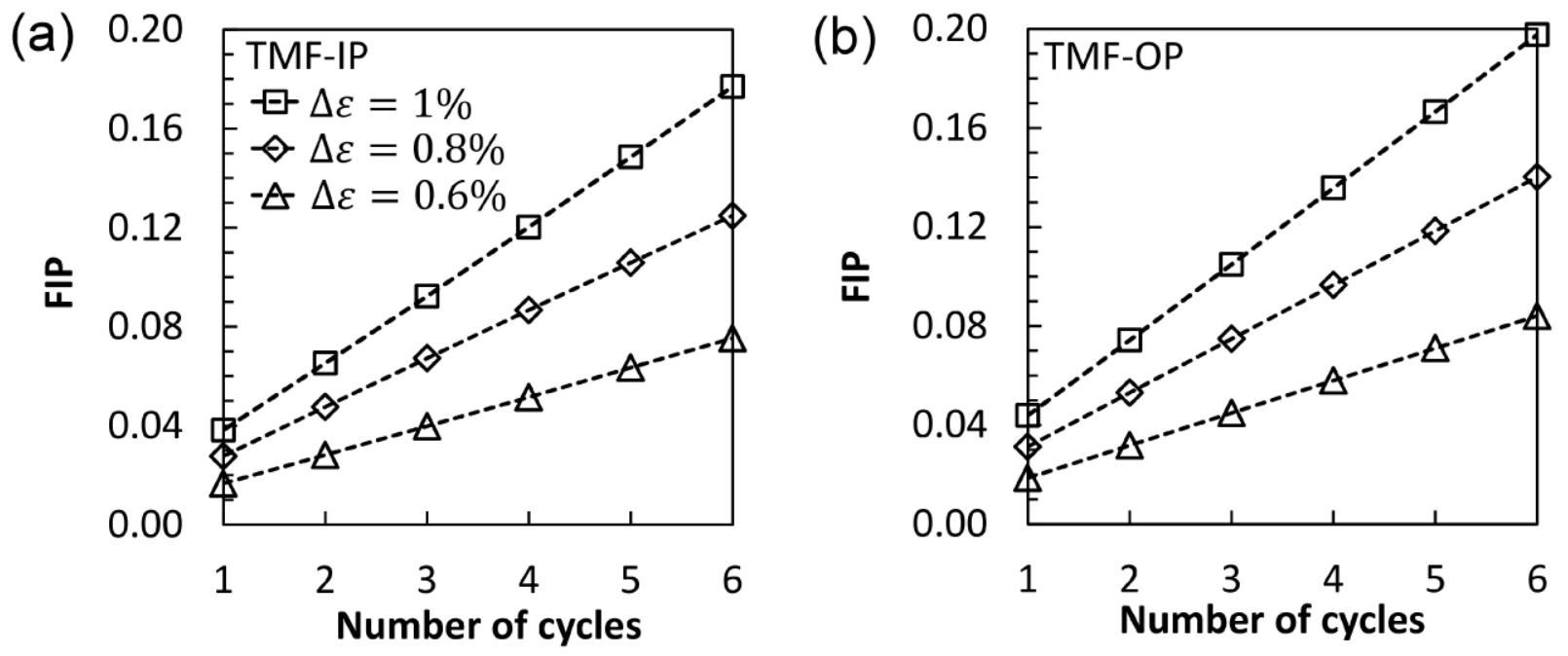

Figure 9: Simulated evolutions of FIP with (a) and (b) the FIP evolution up to six cycles for all mechanical strain ranges under conditions of TMF-IP and TMF-OP, respectively.

Table 3: FIP increment per cycle at different numbers of cycles under different loading conditions.

\begin{tabular}{cccc}
\hline Loading condition & $\triangle$ FIP-early stage & $\triangle$ FIP-half life & Half life cycle \\
\hline TMF-IP; $\triangle \varepsilon=1.0 \%$ & 0.0275 & 0.0291 & 450 \\
TMF-IP; $\triangle \varepsilon=0.8 \%$ & 0.0194 & 0.0220 & 600 \\
TMF-IP; $\triangle \varepsilon=0.6 \%$ & 0.0117 & 0.0145 & 1000 \\
TMF-OP; $\triangle \varepsilon=1.0 \%$ & 0.0308 & 0.0329 & 200 \\
TMF-OP; $\triangle \varepsilon=0.8 \%$ & 0.0208 & 0.0249 & 200 \\
TMF-OP; $\triangle \varepsilon=0.6 \%$ & 0.0131 & 0.0160 & 300 \\
\hline
\end{tabular}

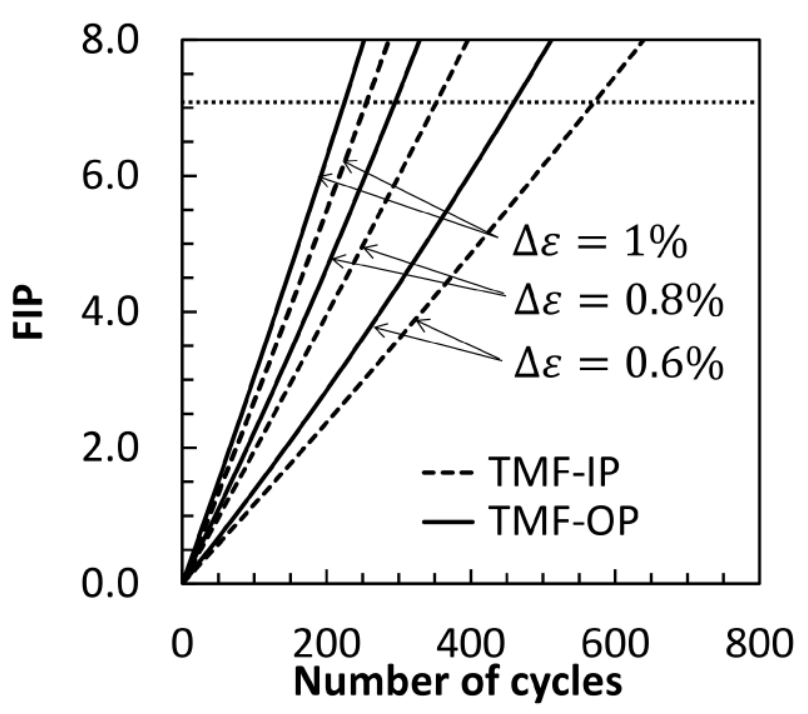

Figure 10: Integrated FIP evolution from the linear function of FIP increment per cycle.

FIP increment per cycle from the early and half-life cycles (by assuming a linear change of the FIP increment), for accurate crack initiation life prediction and these results are shown in Fig. 10. Once the critical value of FIP is identified, then information in terms of the number 
of cycles to crack initiation can be predicted. As given in Eq. (11), $\widetilde{\varepsilon}_{\text {crit }}$ is a material constant. In order to calibrate this, isothermal fatigue test data at $600^{\circ} \mathrm{C}$ are used as experimental inference of FCI has been reported in earlier work [33]. The experimental data from [33] are presented in Fig. 11. The isothermal simulation at $600^{\circ} \mathrm{C}$ with a mechanical strain range of $1 \%$ is used here to calibrate $\widetilde{\varepsilon}_{c r i t}$ and this leads to a critical FIP of 7.1. Based on this value, the number of cycles to fatigue crack initiation can be predicted using Fig. 10 (dotted line) and these results are shown in Fig. 11. It can be seen that TMP-OP is more critical than TMP-IP and this trend is consistent with the experimental data in Fig. 3. Note again, however, that the cycles presented in Fig. 3 are cycles to failure not initiation. As presented in Ref. [33] and discussed in above section, the $N_{i}$ values presented for the $600^{\circ} \mathrm{C}$ IF case are in fact inferred from an analytical Kocks-Mecking softening fit to the experimental softening curves. The point of divergence of the softening fit from the measured response is taken as the initiation number of cycles, $N_{i}$. The $10 \%$ to $20 \%$ trend has been found, in other published work and by the authors in Ref. [33], to be applicable to IF high temperature test data for P91. However, the purpose of this study is to investigate $N_{i}$ for TMF-OP and TMF-IP test data, in comparison with IF data, as shown in Fig. 11. The key point of the results in Fig. 11 is that the $N_{i}$ predicted from the present micro-mechanical CPFE model for TMF-OP and TMF-IP, shows a trend which is consistent with the $N_{f}$ trend of Fig. 3, and, in particular, shows that TMF-OP is more detrimental for $N_{i}$ also. The TMF loading is also more critical than the isothermal loading particularly at the larger mechanical strain ranges. Although the trends discussed here in relation to TMF-OP and TMF-IP, as well as comparative IF data, as shown in Fig. 3, are well known (e.g. [69, 70]), the effects of scatter in fatigue are also well known. To this end, further testing, to establish the effects of scatter on the conclusions presented, is important for future work.

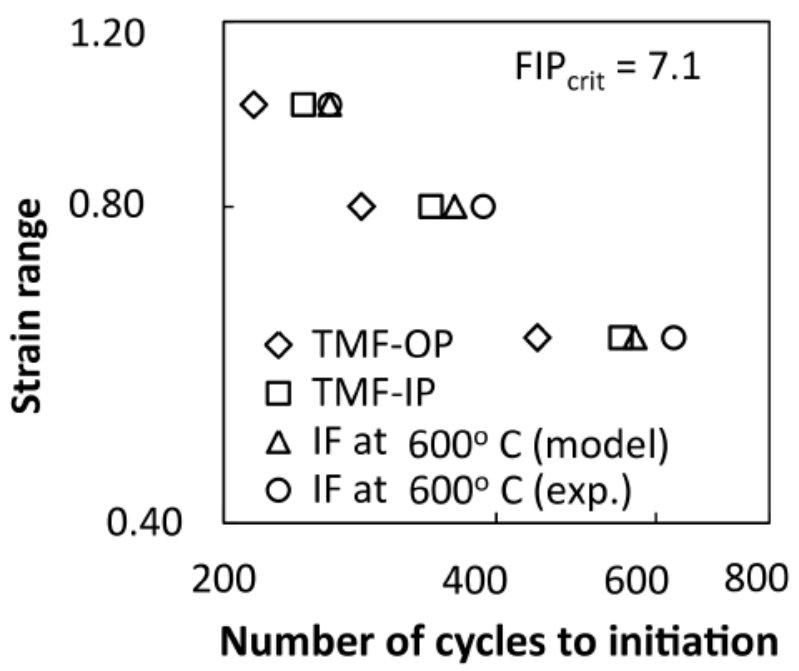

Figure 11: Predicted number of cycles to FCI for TMF and IF and the experimental data for IF.

\subsection{The thermo-mechanical fatigue indicator parameter and its predictive capability}

Comparing with our previous work [33], a new stress-strain-temperature based FIP is developed for assessing FCI during TMF. Incorporation of the temperature dependence of incremental FIP, consistent with TMF loading conditions, is the new aspect. Note that the exponential term of stress triaxiality in Eq. (11) leads to asymmetric accumulation of FIP for 
tension and compression cycles such that more 'fatigue ductility' is used up in tensile cycles than compressive cycles. The temperature-dependent cumulative crystallographic slip term of Eq. (10) results in different accumulations of slip for the TMF-OP and TMF-IP cases, the former being more damaging (Fig. 11). This is simply due to the measured higher ductility for higher temperatures for P91 [71, 62] (captured here via the $\kappa$ term in Eq. (10)), and the assumption of the same functional dependence here for ductility and 'fatigue ductility'. For TMF-OP, the triaxiality term and the temperature term in the proposed FIP are both large when the stress is tensile, whereas for TMF-IP, the temperature term is lower during the tension phase. The temperature term in the FIP definition (Eq. (10)) is lower when the temperature is higher and vice-versa, due to the inverse nature of the temperature term and the fact that at high temperatures, for example, the ductility and hence 'fatigue ductility' of the material is high. Although the data for temperature dependence of ductility is obtained at the macroscopic scale, the present work assumes that its extension to the microstructural level is capable of being used to quantify TMF behaviour, in particular to predict the TMF phase effect (Fig. 11).

Ideally, the calibration of temperature dependence of ductility (parameter $\kappa$ in Eq. (9)) should be based on single crystal fatigue data. However, it is hard to obtain bulk single crystal P91 materials due to the fabrication difficulties. Furthermore, the present work focuses on FCI modelling for TMF, where there is a lack of microscale experimental data. In this sense, further microscale testing for P91 steels is needed. In earlier work, ex-situ electron back scatter diffraction (EBSD [40] has been performed for a small-specimen bending test to investigate the microscale deformation of P91 steel at grain level and the experimental results are in good correlation with crystal plasticity modelling. In-situ micro-testing, such as the in-situ micro Laue diffraction test under low cycle fatigue bending condition [72] (which has been successfully illustrated for coppers), may also be required in future to provide more insight into understanding fatigue mechanisms in P91 steels. Future work will focus on development of micro-crack propagation modelling capability.

\subsection{Thermo-mechanical fatigue assessment for real components}

As indicated in earlier work [5], the complex loading which modern plant components are subjected to results in thermal gradients and ultimately TMF at the component level. Based on a phenomenological continuum model and multiaxial fatigue criterion, TMF life of real plant under realistic loading has been predicted in Ref. [5]. The present work indicates that the influence of TMF can be effectively predicted at the microstructural level. Hence, a more accurate assessment procedure for TMF life of real plant components may be formulated by combining the previous model [5] at component level and the current micromechanical model in a top-down manner. The input of temperature and mechanical strain to the micromechanical model can be obtained directly from the FE modelling at component level. On the other hand, the microstructural effect on TMF life of a real component may also be examined using this modelling framework.

\section{Conclusions}

The key conclusions of this paper are as follows:

1. The detrimental effect of the in-phase and out-of-phase strain-temperature controlled (between $400^{\circ} \mathrm{C}$ and $600^{\circ} \mathrm{C}$ ) thermo-mechanical cycles on a tempered martensite ferritic steel (P91) is demonstrated experimentally, relative to isothermal fatigue testing at 
$400^{\circ} \mathrm{C}, 500^{\circ} \mathrm{C}$ and $600^{\circ} \mathrm{C}$. In all cases, significant cyclic softening is observed. Significantly shorter lives are obtained for the thermo-mechanical fatigue than for isothermal fatigue, with out-of-phase giving the shortest lives.

2. A micromechanical model using strain-gradient crystal plasticity is developed for P91 steel, using measured EBSD, and calibrated for early and half-life thermo-mechanical cycles via isothermal fatigue test data at $400^{\circ} \mathrm{C}, 500^{\circ} \mathrm{C}$ and $600^{\circ} \mathrm{C}$. The only temperaturedependent parameters are the elastic constants and a kinematic hardening modulus. The half-life calibration is achieved by evolution (reduction) of initial dislocation density (consistent with measured data from the literature) and critical resolved shear stress. The cyclic plasticity model is successfully validated by accurate prediction of hysteresis loop shapes across a range of strain-ranges, for isothermal fatigue at $400^{\circ} \mathrm{C}, 500^{\circ} \mathrm{C}$ and $600^{\circ} \mathrm{C}$ and, more specifically here, for both in-phase and out-of-phase thermomechanical tests between $400^{\circ} \mathrm{C}$ and $600^{\circ} \mathrm{C}$. Furthermore, more detailed investigation of the effect of temperature on the evolution of dislocation densities as future work would clearly be beneficial for improved understanding of microscale thermo-mechanical fatigue response.

3. A novel accumulated crystallographic slip fatigue indicator parameter for fatigue crack initiation in thermo-mechanical fatigue is developed. The parameter is an adaptation of a triaxiality-dependent parameter, previously validated for isothermal fatigue at $600^{\circ} \mathrm{C}$; the adaptation is the introduction of a temperature term, based on the measured functional dependency of temperature on failure strain (monotonic).

4. The new parameter predicts that out-of-phase thermo-mechanical fatigue is more detrimental than in-phase, which in turn is more detrimental than isothermal, respectively, vis-à-vis crack initiation. This is consistent with the measured total fatigue life data for the respective cases. Quantitative validation of the crack initiation parameter has been previously demonstrated for isothermal tests at $600^{\circ} \mathrm{C}$, inferred from the softening curves. It has not yet been possible to infer initiation lives from the thermo-mechanical softening curves. Future work will address this, via the development of improved dislocation density evolution softening equations for the micro-mechanical model presented here and interrupted thermo-mechanical fatigue testing.

\section{Acknowledgment}

This publication has emanated from research conducted with the financial support of Science Foundation Ireland under grant number SFI/10/IN.1/I3015. The modelling work was supported by the Irish Center for High-End Computing (ICHEC). Helpful discussions with Dr. Peter Tiernan, Mr. Brian Golden and Dr. Yina Guo of the Materials and Surface Science Institute (MSSI) at University of Limerick, Ireland, and Mr. Stephen Scully and Ms. Adelina Adams of ESB Energy International, Ireland are gratefully acknowledged.

\section{References}

[1] McDowell DL, Dunne FPE. Microstructure-sensitive computational modeling of fatigue crack formation. Int J Fatigue 2010;32:1521-1542.

[2] Sangid MD. The physics of fatigue crack initiation. Int J Fatigue 2013;57:58-72.

[3] Dunne FPE. Fatigue crack nucleation: Mechanistic modelling across the length scales. Curr Opin Solid State Mater Sci 2014;18:170-179.

[4] Farragher TP, Scully S, O'Dowd NP, Leen S.B. Thermomechanical Analysis of a Pressurized Pipe Under Plant Conditions. J Press Ves Tech-Trans ASME, 2013;135:011204-9. 
[5] Farragher TP, Scully S, O'Dowd NP, Leen S.B. Development of life assessment procedures for power plant headers operated under flexible loading scenarios. Int J Fatigue, 2013;49:50-61.

[6] Sauzay M, Brillet H, Monnet I, Mottot M, Barcelo F, Fournier B, Pineau A. Cyclically induced softening due to low-angle boundary annihilation in a martensitic steel. Mater Sci Eng A 2005;400-401:241-4.

[7] Sauzay M, Fournier B, Monnet I, Mottot M, Pineau A. Cyclic softening of martensitic steels at high temperature-experiments and physically based modelling. Mater Sci Eng A 2008;483-484:410-4.

[8] Fournier B, Dalle F, Sauzay M, Longour J, Salvi M, Caës C, Tournié I, Giroux PF, Kim SH. Comparison of various $9-12 \% \mathrm{Cr}$ steels under fatigue and creep-fatigue loadings at high temperature, Mater Sci Eng A 2011;528:6934-45.

[9] Farragher TP, Hyde CJ, Sun W, Hyde TH, O'Dowd NP, Scully S, Leen SB. High temperature low cycle fatigue behaviour of service-aged P91 material, in: $9^{\text {th }}$ International Conference on Creep and Fatigue at Elevated Temperatures, IOM3, London, UK, 2012.

[10] Hyde CJ, Sun W, Hyde TH, Rouse JP, Farragher TP, Leen SB. Cyclic visco-plasticity testing and modelling of a service-aged P91 steel, in: Proceedings of the ASME 2012 Pressure Vessels and Piping Division Conference, ASME, Toronto, Ontario, Canada, 2012.

[11] Mayer T, Balogh L, Solenthaler C, Müller Gubler E, Holdsworth SR. Dislocation density and sub-grain size evolution of 2CrMoNiWV during low cycle fatigue at elevated temperatures. Acta Mater 2012;60:2485-96.

[12] Barrett RA, O'Donoghue PE, Leen SB. An improved unified viscoplastic constitutive model for strain-rate sensitivity in high temperature fatigue. Int J Fatigue 2013;48:192-204.

[13] Barrett RA, Farragher TP, O'Dowd NP, O'Donoghue PE, Leen SB. Multiaxial cyclic viscoplasticity model for high temperature fatigue of P91 steel. Mater Sci Tech 2014;30(1):67-74.

[14] Barrett RA, Farragher TP, Hyde CJ, O'Dowd NP, O'Donoghue PE, Leen SB. A unified viscoplastic model for high temperature low cycle fatigue of service-aged P91 steel. J Press Ves Tech-Trans ASME 2014;136:024102.

[15] Hu X, Huang L, Yan W, Wang W, Sha W, Shan Y, Yang K. Low cycle fatigue properties of CLAM steel at 823 K. Mater Sci Eng A 2014;613:404-13.

[16] Farragher TP. Thermomechanical Analysis of P91 Power Plant Components. PhD Thesis, Mechanical Engineering, NUI Galway, Ireland, 2014.

[17] Saad AA, Hyde CJ, Sun W, Hyde TH. Thermal-mechanical fatigue simulation of a P91 steel in a temperature range of $400-600^{\circ}$ C, Mater High Temp 2011;28:212-8.

[18] Manonukul A, Dunne FPE. High and lowcycle fatigue crack initiation using polycrystal plasticity. Proc Royal Soc Lond 2004;460:1881-903.

[19] Findley KO, Saxena A. Low cycle fatigue in rene $88 \mathrm{DT}$ at $650^{\circ}$ C: Crack nucleation mechanisms and modeling. Metall Mater Trans A 2006;37:1469-75.

[20] Dunne FPE, Wilkinson AJ, Allen R. Experimental and computational studies of low cycle fatigue crack nucleation in a polycrystal. Int J Plast 2007;23:273-95.

[21] Korsunsky AM, Dini D, Dunne FPE, Walsh MJ. Comparative assessment of dissipated energy and other fatigue criteria. Int J Fatigue 2007;29:1990-5.

[22] McDowell DL. Simulation-based strategies for microstructure-sensitive fatigue modeling. Mater Sci Eng A 2007;468-470:4-14.

[23] Shenoy M, Tjiptowidjojo Y, McDowell D. Microstructure-sensitive modeling of polycrystalline IN 100. Int J Plast 2008;24:1694-730.

[24] McDowell DL. Microstructure-sensitive modeling and simulation of fatigue. In: ASM handbook on modeling and simulation: processing of metallic materials 2009;22A:408-418.

[25] Przybyla CP, McDowell DL. Microstructure-sensitive extreme value probabilities for high cycle fatigue of Ni-base superalloy IN100. Int J Plast 2010;26:372-94.

[26] Anahid M, Samal MK, Ghosh S. Dwell fatigue crack nucleation model based on using crystal plasticity finite element simulations of polycrystalline Titanium alloys. J Mech Phys Solids 2011;59:2157-76.

[27] Przybyla CP, McDowell DL. Simulated microstructure-sensitive extreme value probabilities for high cycle fatigue of duplex Ti-6Al-4V. Int J Plast 2011;27:1871-95.

[28] Anahid M, Ghosh S. Homogenized constitutive and fatigue nucleation models from crystal plasticity FE simulations of Ti alloys, Part 2: Macroscopic probabilistic crack nucleation model. Int J Plast 2013;48:11124.

[29] Ghosh S, Anahid M. Homogenized constitutive and fatigue nucleation models from crystal plasticity FE simulations of Ti alloys, Part 1: Macroscopic anisotropic yield function. Int J Plast 2013;47:182-201.

[30] McCarthy OJ, McGarry JP, Leen SB. Microstructure-sensitive prediction and experimental validation of fretting fatigue. Wear 2013;305:100-14.

[31] Sweeney CA, Vorster W, Leen SB, Sakurada E, McHugh PE, Dunne FPE. The role of elastic anisotropy, 
length scale and crystallographic slip in fatigue crack nucleation. J Mech Phys Solids 2013;61:1224-40.

[32] Sweeney CA, O'Brien B, Dunne FPE, McHugh PE, Leen SB. Strain-gradient modelling of grain size effects on fatigue of CoCr alloy. Acta Mater 2014;78:341-53.

[33] Li DF, Barrett RA, ODowd NP, ODonoghue PE, Leen SB. A multi-scale crystal plasticity model for cyclic plasticity and low-cycle fatigue in P91 steel at elevated temperature. 2015; Submitted for publication.

[34] Patra A, McDowell DL. Crystal plasticity-based constitutive modeling of irradiated bcc structures. Philos Mag 2012;92(7):861-87.

[35] Ghassemi-Armaki H, Chen P, Bhat S, Sadagopan S, Kumar S, Bower A. Microscale-calibrated modeling of the deformation response of low-carbon martensite. Acta Mater 2013;61:3640-52.

[36] Li DF, Golden BJ, O'Dowd NP. Modelling of micro-plasticity evolution in crystalline materials. Proceedings of 2013 ASME Pressure Vessels and Piping Division Conference, July 2013, Paris, France.

[37] Shanthraj P, Zikry MA. Microstructurally induced fracture nucleation and propagation in martensitic steels. J Mech Phys Solids 2013;61:1091-105.

[38] Golden BJ, Li DF, O’Dowd NP, Tiernan P. Microstructural modeling of P91 martensitic steel under uniaxial loading conditions. J Press Ves Tech-Trans ASME 2014;136:021404.

[39] Li DF, Golden BJ, O'Dowd NP. Multiscale modelling of mechanical response in a martensitic steel: A micromechanical and length-scale-dependent framework for precipitate hardening. Acta Mater 2014;80:44556.

[40] Golden BJ, Li DF, Guo YN, Tiernan P, Leen SB, O'Dowd NP. Microscale deformation of a tempered martensite ferritic steel: Modelling and experimental study of grain and sub-grain interactions. J Mech Phys Solids 2016;86:42-52.

[41] Barrett RA. Experimental Characterisation and Computational Constitutive Modelling of High Temperature Degradation in 9Cr Steels Including Microstructural Effects. PhD Thesis, Mechanical Engineering, NUI Galway, Ireland, 2016.

[42] Li DF, O'Dowd NP, On the evolution of lattice deformation in austenitic stainless steels-The role of work hardening at finite strains. J Mech Phys Solids 2011;59:2421-41.

[43] Busso EP, McClintock FA. A dislocation mechanics-based crystallographic model of a B2-type intermetallic alloy. Int J Plast 1996;12(1):1-28.

[44] Armstrong PJ, Frederick CO. A Mathematical Representation of the Multiaxial Bauschinger Effect, CEGB Report, RD/B/N731, Berkeley Nuclear Laboratories, 1966.

[45] Busso EP. Cyclic deformation of monocrystalline nickel allumindide and high temperature coatings. PhD thesis, Department of Mechanical Engineering, Massachusetts Institute of Technology, USA, 1990.

[46] Li DF, Davies CM, Zhang SY, Dickinson C, O'Dowd NP. The effect of prior deformation on subsequent microplasticity and damage evolution in an austenitic stainless steel at elevated temperature. Acta Mater 2013;61:3575-84.

[47] Franciosi P, Berveiller M, Zaoui A. Latent hardening in copper and aluminium sigle crystals. Acta Metall $1980 ; 28(3): 273-83$.

[48] Ma A, Roters F, Raabe D. A dislocation density based constitutive model for crystal plasticity FEM including geometrically necessary dislocations. Acta Mater 2006;54:2169-79.

[49] Cheong KS, Busso EP. Discrete dislocation density modelling of single crystal fcc polycrystals. Acta Mater 2004;52:5665-75.

[50] Cheong KS, Busso EP. Effects of lattice misorientations on strain heterogeneities in fcc polycrystals. J Mech Phys Solids 2006;54:671-89.

[51] Rebstock H. Kombinierte zug-und torsionsverformung von kupbfer-einkristallrohen. Z Metallk 1957;48:206-20.

[52] Mader S. Elektronmikroskopische untersuchung der gleitlinienbildung auf kupfereinkristallen. Z Phys 1957;149:73-102.

[53] Mughrabi H. Cyclic slip irreversibility and fatigue life: A microstructure-based analysis. Acta Mater 2013;61:1197-203.

[54] ABAQUS V6.11, Hibbitt, Karlsson and Sorensen Inc., Providence, RI, USA, 2011.

[55] Miyahara M, et al. Proceeding of the 31st Symposium on Strength of Materials at High Temperature 50-54, in Japanese, 1993.

[56] Nonaka, I., et al. Recent techniques for residual life assessment of aged fossil power plant materials. IHI J 1996;36(4), in Japanese.

[57] Okamura H, Ohtani R, Saito K, Kimura K, Ishii R, Fujiyama K, Hongo S, Iseki T, Uchida H. Basic investigation for life assessment technology of modified 9Cr-1Mo steel. Nucl Eng Des 1999;193:243-54.

[58] Sweeney CA, OBrien B, Dunne FPE, McHugh PE, Leen SB. Micro-scale testing and micromechanical modelling for high cycle fatigue of CoCr stent material. J Mech Behav Biomed Mater 2015;46:244-60. 
[59] Kuwamura H. Transtion between fatigue and ductile fracture in steel. J Struct Eng 1997;123(7):864-70.

[60] Rosien FJ, Ostertag CP. Low cycle fatigue behaviour of constraint connections. Mater Struct 2009;42:16170.

[61] Kiran R, Khandelwal K. A micromechanical cyclic void growth model for ultra-low cycle fatigue. Int J Fatigue 2015;70:24-37.

[62] Golden BJ, Li DF, Tiernan P, Scully S, ODowd NP. Deformation characteristics of a high-chromium, power plant steel at elevated temperatures. 2016;Submitted for publication.

[63] Li DF, Golden BJ, Zhang SY, Davydov V, Tiernan P, O'Dowd NP. The role of plasticity in the transverse lattice strain evolution of a martensitic steel. Metall Mater Trans A 2014;45A:5829-33.

[64] Li DF, Golden BJ, Zhang SY, O’Dowd NP. In-situ lattice strain evolution of a P91 steel by means of neutron diffraction and crystal plasticity modelling. 2015;Manuscript in preparation.

[65] Hyde CJ, Sun W, Leen SB. Cyclic thermo-mechanical material modelling and testing of 316 stainless steel. Int J Pres Ves Pip 2010;87:365-72.

[66] Giroux PF. Experimental study and simulation of cyclic softening of tempered martensite ferritic steels. Ph.D. thesis, l'Ecole Nationale Superieure des Mines de Paris (2011)

[67] Orowan E. Symposium on internal stresses. In: Metals and alloys. London: Institute of Metals; 1948.

[68] Barrett RA, O’Donoghue PE, Leen SB. A dislocation-based model for high temperature cyclic viscoplasticity of 9-12Cr steels. Comp Mater Sci 2014;92:286-97.

[69] Huang ZW, Wang ZG, Zhu SJ, Yuan FH, Wang FG. Thermomechanical fatigue behavior and life prediction of a cast nickel-based superalloy. Mater Sci Eng A 2006;432:308-16.

[70] Chen W, Dudka A, Chen H, Mukherji D, Wahi RP, Wever H. In: Bressers J, Remy L, Steen M, Valles JL, editors. Procedings of a symposium on fatigue under thermal and mechanical loading: Mechanisms, mechanis and modelling, Petten, May 22-24, 1995. The Netherlands: Kluwer Academic Publishers; 1996;p.:97-102.

[71] Wang L, Li M, Almer J, In situ characterization of Grade 92 steel during tensile deformation using concurrent high energy X-ray diffraction and small angle X-ray scattering. Acta Mater 2013;440:81-90.

[72] Kirchlechner C, Imrich PJ, Liegl W, Pörnbacher J, Micha JS, Ulrich O, Motz C. On the reversibility of dislocation slip during small scale low cycle fatigue. Acta Mater 2015;94:69-77. 